Students" series. "A Further Handbook of Industrial Radiology" written by fifteen members of the Non-Destructive Testing Group and edited by W. J. Wiltshire, and a fourth selection of "Laboratory and Workshop Notes" reprinted from the 1953-55 Journal of Scientific Instruments, compiled and edited by Dr. Ruth Lang, were published by Edward Arnold (Publishers), Ltd., for the Institute.

The third convention of the Institute, held in Oxford during July 10-13, was attended by about 250 members, ladies and guests, a rather smaller attendance than expected. Lectures were delivered by Prof. N. F. Mott on dislocations and the physics of materials and by Prof. A. C. B. Lovell on recent advances in radio-astronomy. The address given by Sir Cyril Hinshelwood on July 11 in the Sheldonian Theatre on "Physics among the Sciences" was published in the September issue of the Bulletin $(8,300 ; 1957)$ and the lecture by Mr. Alan Bullock on July 12 on "Science and the Humanities" in the December issue $(8,380 ; 1957)$.

The Institute has nine branches in Great Britain, a Malayan branch under the chairmanship of Mr. Hon Yung Sen and an Australian branch with divisions in different states under the presidency of Dr. F. W. G. White. The New South Wales division formed a solid-state physics group, the first specialist group to be formed in the Australian branch. In addition to the branches in Great Britain, there are seven specialist subject groups-applied spectroscopy, education, electronics, electron microscopy, non-destructive testing, stress analysis and $\mathrm{X}$-ray analysis-which arrange their own programmes of scientific meetings and conferences.
The Board through its permanent officers has continued to give advice in answer to individual inquiries concerning professional matters, and in quirers requesting assistance in filling vacancies for physicists were advised to advertise in the Bulletin, which has now become a recognized medium for this purpose. In reply to the Scientific Manpower Committee of the Government's Advisory Council on Scientific Policy the Board stated that the members of the Board were generally agreed that if the number of graduates in physics were doubled within five to ten years the demand could still exceed the supply, and that the Board was perturbed by the number of first-class physicists who were leaving the country for permanent employment overseas. The results of the fourth survey of salaries and emoluments paid to fellow, associate and graduate members of the Institute were published in the January issue of the Bulletin (8, 19 ; 1957) and reprints were widely distributed. Discussions with the Physical Society for closer collaboration between the Institute and tné Society have progressed favourably, and an announcement of interest will shortly be made.

To mark the completion of twenty-five years as secretary and editor, and in recognition of his services to the Institute, a presentation was made by the Board to Dr. H. R. Lang.

At the general meeting of the Institute, the following were elected to take office on October 1 : president, Sir George Thomson; vice-president, Dr. R. W. Sellars; hon. treasurer, Dr. J. Taylor; hon. secretary, Prof. F. A. Vick. Sir William Lawrence Bragg was elected to Honorary Fellowship. S. WeINTRoub

\title{
COUNCIL FOR THE PRESERVATION OF RURAL ENGLAND
}

$\mathrm{T}$ HE thirty-second annual report* of the Council for the Preservation of Rural England, covering the period May 1957 to April 1958, again stresses the impact which the nuclear power programme is likely to have on the appearance of the countryside. Probably less than a tenth of the population are directly concerned with the land, and it is the urban majority which dictates, in the main, the shape of future developments. The Council welcomes the formation, on Mr. Duncan Sandys's initiative, of the Civic Trust for the encouragement of good architecture and civic planning and the stimulation of interest of urban and suburban dwellers in the visual aspect of town and country and the avoidance of unsightly develop. ment. The work of the Council itself continued along the same general lines, but the volume and range of work undertaken continued to increase.

The report provides a very useful summary of the bearing on the preservation of the countryside of recent legislation, such as the Electricity Act, 1957, the Winfrith Heath Act, 1957, the Local Government Bill, the Opencast Coal Bill, the Tribunals and Inquiries Bill and the Water Bill. Considerable discussion and correspondence has taken place between the Council and the Ministry of Housing and Local Government in regard to the recommendations of the Franks report

* Council for the Preservation of Rural England. Thirty-second Annual Report, 1957-1958. Pp. 64 +4 plates. (London: Council for
the Preservation of Rural England, 1958.) relating to inspectors' reports, and the Ministry has agreed to supply the Council or its branches with copies of such reports on request. The use of land by Service Departments continued to demand much attention, and concern is expressed at the tendency of the Electricity Authorities to adopt the line of least resistance. The protracted negotiations regarding the routing of the electricity supply to the television station on Sandale Fell (Cumberland) are described in some detail as illustrating the meticulous care taken by the Minister of Power to give effect to his undertaking to try to reconcile the claims of landscape beauty with the urgent need to provide electricity in rural areas as economically as possible.

Numerous other instances are cited in the report in which the Council has had to raise objections, and mineral undertakings and roads and footpaths have also been the source of much anxiety, particularly the use of the Kendal to Keswick road over Dunmail Raise by heavy industrial traffic. The Council urges strongly that heavy industrial traffic should be discouraged from using this road by suitable improvements to the west coast road to make this an attractive alternative, and also by developing the alternative route through the Lune valley. This matter is regarded as particularly urgent, and the problem is being thoroughly investigated by traffic experts of the Automobile Association and the Royal Automobile Club. 